\title{
Hypopituitarism Associated with Cogan's Syndrome; High-dose Glucocorticoid Therapy Reverses Pituitary Swelling
}

\author{
Masanori KANATANI, Ryohji NAKAMURA, Keizo KUROKAWA, Masahiko TAODA, \\ Yoko NEMOTO, Keiko KAMAKURA, Nobuo KUGAI, Naokazu NAGATA, \\ Osamu TAKATANI and Kazuhiro TSUCHIYA*
}

\begin{abstract}
A 70-year-old woman with Cogan's syndrome first presented with central diabetes insipidus and then developed secondary hypothyroidism. Magnetic resonance imaging revealed a diffuse pituitary swelling without evidence of tumor. High-dose glucocorticoid therapy administered to treat Cogan's syndrome was very effective in suppressing the inflammatory process, and resulted in the reversal of the pituitary swelling and partial recovery of thyroid stimulating hormone secretion. This is the first case of hypopituitarism associated with Cogan's syndrome, a form of autoimmune vasculitis. The glucocorticoid-responsive pituitary lesion is best explained by autoimmune hypophysitis which shows pituitary swelling and is known to often associate with other autoimmune phenomena.
\end{abstract}

Key words: Lymphocytic hypophysitis, Central diabetes insipidus, Magnetic resonance imaging, Pituitary swelling

Cogan's syndrome is a rare clinical entity characterized by non-syphilitic interstitial keratitis with vestibuloauditory dysfunction (1). The pathogenesis of this syndrome is now considered to be systemic vasculitis, and there are many case reports associated with additional clinical problems such as heart, musculoskeletal, nerve and lymph node involvement $(2,3)$. However, none of the patients with Cogan's syndrome has been reported to manifest endocrinopathy. Herein we report the first case of Cogan's syndrome with an accompanying pituitary lesion resulting in central diabetes insipidus and secondary hypothyroidism. Magnetic resonance imaging (MRI) revealed a diffuse pituitary swelling which was reversed after a high-dose glucocorticoid therapy.

\section{CASE REPORT}

A 70-year-old woman was admitted to our hospital on January 24, 1989 because of headache, polyuria and polydipsia. She was well until 4 months before the admission when she began to experience headache along with vertigo and hyperemia of the left bulbar conjunctiva. A month before admission, she noticed the abrupt onset of polydipsia and polyuria. She had experienced three uneventful deliveries. Her menopause was at the age of 58 . There was a history of mild hypertension for the last two yr.

Examination on admission revealed a moderately obese woman whose wt was $53 \mathrm{~kg}$ and ht $143 \mathrm{~cm}$. Her body temperature was $37.3^{\circ} \mathrm{C}$, pulse $104 / \mathrm{min}$, and blood pressure $160 / 100 \mathrm{mmHg}$. The tongue was

From The Third Department of Internal Medicine and *The Department of Radiology, National Defense Medical College, Tokorozawa

Received for publication January 9, 1990; Accepted for publication October 25, 1990

Reprint requests should be addressed to Naokazu Nagata, MD, The Third Department of Internal Medicine, National Defense Medical College, Tokorozawa 359, Japan 
dry. The left bulbar conjunctiva was hyperemic and was diagnosed as scleritis. The thyroid gland was not palpable. Optic fundi and the visual fields were normal. Neurological examination was negative except for nystagmus and left hearing loss confirmed by electronystagmography and audiogram, respectively. Urine gave a normal urinalysis with a specific gravity of 1010 . The hemoglobin concentration was $14.9 \mathrm{~g} / \mathrm{dl}$ with a normochromic normocytic film; the white cell count was $13,200 / \mathrm{mm}^{3}$ with $7 \%$ band forms, $59 \%$ segmented neutrophils, $28 \%$ lymphocytes and $6 \%$ monocytes; the platelet count was $401,000 / \mathrm{mm}^{3}$. The erythrocyte sedimentation rate (ESR) was $49 \mathrm{~mm} / \mathrm{h}$ and C-reactive protein (CRP) was $0.4 \mathrm{mg} / \mathrm{dl}$. The serum level of $\mathrm{Na}$ was $147 \mathrm{mEq} / \mathrm{l}, \mathrm{K} 4.1 \mathrm{mEq} / \mathrm{l}, \mathrm{Cl}$ $107 \mathrm{mEq} / \mathrm{l}$, Ca $8.6 \mathrm{mg} / \mathrm{dl}$ and $\mathrm{P} 4.3 \mathrm{mg} / \mathrm{dl}$. The serum glucose level was $99 \mathrm{mg} / \mathrm{dl}$ and urea nitrogen $16 \mathrm{mg} / \mathrm{dl}$. The plasma osmolality was $290 \mathrm{mOsm} / \mathrm{Kg}$ - $\mathrm{H}_{2} \mathrm{O}$ and that of urine was $121 \mathrm{mOsm} / \mathrm{Kg} \cdot \mathrm{H}_{2} \mathrm{O}$. Serum angiotensin converting enzyme activity was $15.4 \mathrm{U} / \mathrm{ml}$. Antinuclear antibodies were negative and $\mathrm{CH}_{50}$ was $48.4 \mathrm{U} / \mathrm{ml}$. Anti-microsomal and antithyroglobulin antibodies were positive at titers of $1: 400$ and $1: 400$, respectively, but antipituitary antibodies reacting against plasma membrane of AtT-20 and $\mathrm{GH}_{3}$ cells or cytoplasm of rat pituitary cells were all negative (Biomedical Laboratories, Kawagoe, Saitama). Tuberculin skin test was positive. X-ray studies of the chest and skull were unremarkable.

During $8 \mathrm{~h}$ of water deprivation, the plasma osmolality increased from 295 to $301 \mathrm{mOsm} / \mathrm{Kg}$ • $\mathrm{H}_{2} \mathrm{O}$, those of urine from 104 to $412 \mathrm{mOsm} / \mathrm{Kg}$ • $\mathrm{H}_{2} \mathrm{O}$, and serum antidiuretic hormone (ADH) from 1.0 to $1.2 \mathrm{pg} / \mathrm{ml}$. After vasopressin injection, urine osmolality was $466 \mathrm{mOsm} / \mathrm{Kg} \cdot \mathrm{H}_{2} \mathrm{O}$ at $60 \mathrm{~min}$. Central partial diabetes insipidus was diagnosed and nasal desamino-8-D-arginine vasopressin (DDAVP) treatment successfully controlled urine volume.

The plasma levels of free triiodothyronine $\left(\mathrm{T}_{3}\right)$ was $2.9 \mathrm{pg} / \mathrm{ml}$, free thyroxin $\left(\mathrm{T}_{4}\right) 1.23 \mathrm{ng} / \mathrm{dl}$, cortisol $17.8 \mu \mathrm{g} / \mathrm{dl}$ and estradiol $49.8 \mathrm{pg} / \mathrm{ml}$. The anterior pituitary function was fairly well preserved (Table 1). Computed tomographic (CT) scan and MRI (Fig. 1A) showed diffuse homogenous swelling of the pituitary extending to its stalk. On MRI, no difference in intensity could be discerned between anterior and posterior lobes. Surgical exploration of the pituitary was not performed because the possibility of a pituitary tumor was low, and she was discharged on $15 \mu \mathrm{g} /$ day of DDAVP.

Severe headache continued, and she was readmitted a month later. Shortly before the readmission, she began to feel cold intolerance and her serum levels of free $\mathrm{T}_{4}$ and thyroid-stimulating hormone (TSH), both basal and stimulated, were low (Fig. 2 and Table 1). Levels of gonadotropins, both basal and luteinizing hormone ( $\mathrm{LH}$ )-releasing hormone (LHRH) stimulated, were also lower than those observed during the first admission; moderate hyperprolactinemia was also noted (Table 1). Plasma level of cortisol was $16 \mu \mathrm{g} / \mathrm{dl}$ in the morning.

The cold intolerance disappeared by the replace-

Table 1. Summary of the Results of Anterior Pituitary Function Tests

\begin{tabular}{llllllll}
\hline & & \multicolumn{2}{c}{ First admission } & \multicolumn{5}{c}{ Second admission } \\
& & & \multicolumn{2}{c}{ Before PSL treatment } & After PSL treatment \\
\hline & & Basal & Peak* $^{*}$ & Basal & Peak $^{*}$ & Basal & Peak* $^{*}$ \\
\hline $\mathrm{GH}$ & $\mathrm{ng} / \mathrm{ml}$ & 0.3 & 9.6 & 0.8 & - & 0.3 & 2.8 \\
$\mathrm{PRL}$ & $\mathrm{ng} / \mathrm{ml}$ & 10 & 77 & 40 & 88 & 14 & 76 \\
$\mathrm{LH}$ & $\mathrm{mIU} / \mathrm{ml}$ & 6.1 & 42 & 0.9 & 33 & 4.1 & 16 \\
$\mathrm{FSH}$ & $\mathrm{mIU} / \mathrm{ml}$ & 32 & 67 & 15 & 36 & 16 & 27 \\
$\mathrm{TSH}$ & $\mu \mathrm{U} / \mathrm{ml}$ & 0.9 & 5.8 & $<0.1$ & 0.3 & 0.4 & 1.9 \\
$\mathrm{ACTH}$ & $\mathrm{pg} / \mathrm{ml}$ & 42 & $470^{* *}$ & 54 & - & - & - \\
\hline
\end{tabular}

* Maximal values after combined stimulation with div arginine $0.5 \mathrm{~g} / \mathrm{kg}$, iv TRH $500 \mu \mathrm{g}$ and iv LHRH $100 \mu \mathrm{g} .{ }^{* *}$ Value after overnight metyrapon test $(30 \mathrm{mg} / \mathrm{kg} \mathrm{po})$. PSL, prednisolone 
A

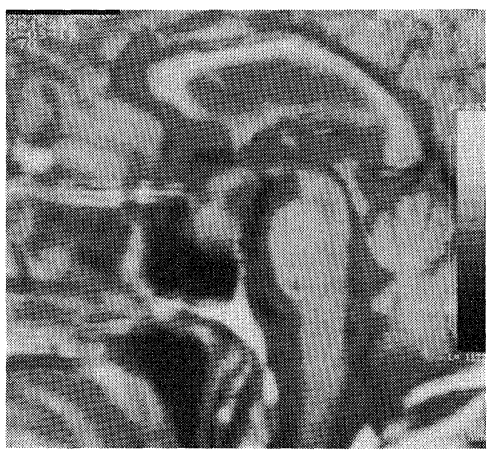

B

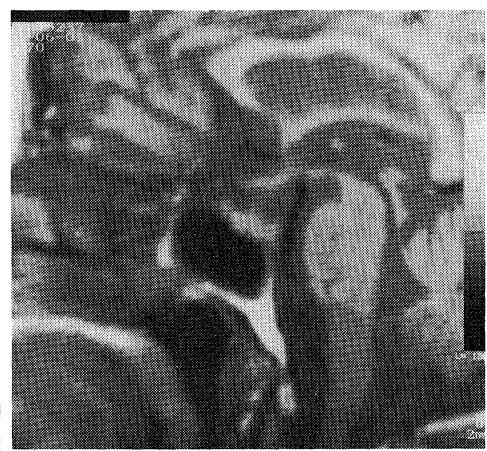

Fig. 1. A) MRI taken at the first admission shows swelling of the pituitary stalk and the pituitary gland. B) Follow-up MRI 2 wk after the initiation of prednisolone therapy shows the disappearance of pituitary swelling.

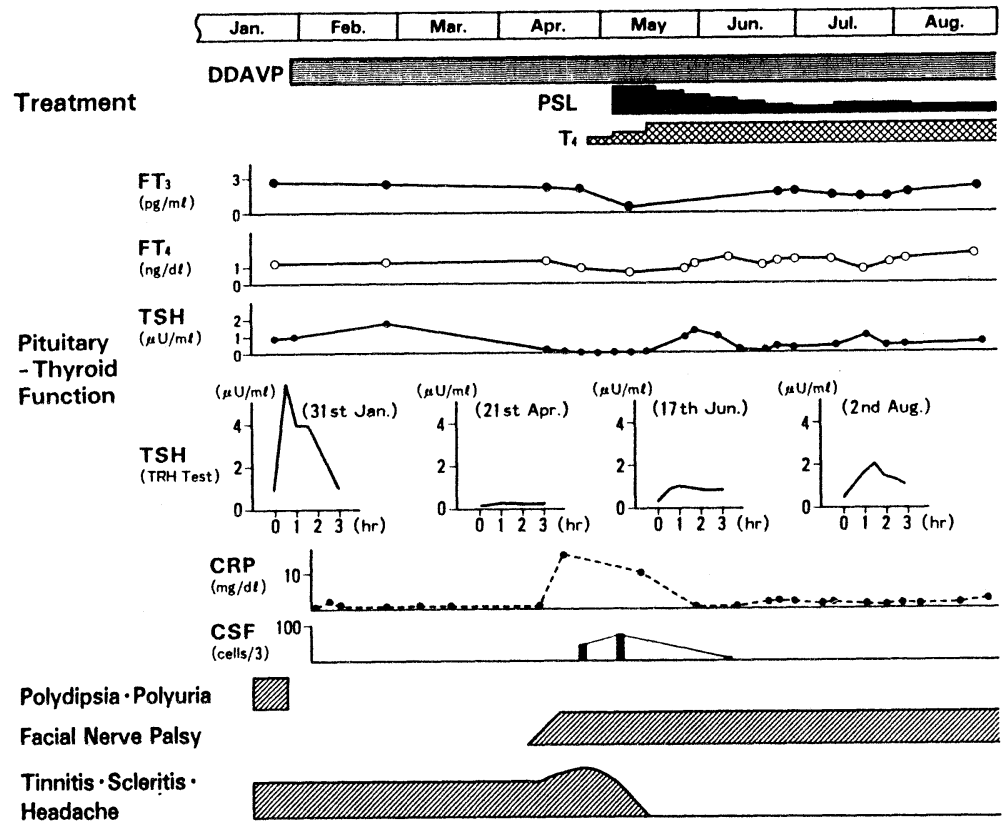

Fig. 2. Clinical course. As the symptoms of Cogan's syndrome became exacerbated, secondary hypothyroidism progressed gradually. Prednisolone therapy improved not only the symptoms of Cogan's syndrome but also the basal and TRH-stimulated levels of serum TSH.

ment of thyroxin ( $50 \mu \mathrm{g} /$ day), but scleritis and vertigo persisted and headache with nuchal rigidity increased in intensity. On April 20, painful bilateral parotid gland swelling and left facial nerve palsy were noticed. The white blood cell count was $14,300 / \mathrm{mm}^{3}$, ESR $94 \mathrm{~mm} / \mathrm{h}$ and CRP $16.0 \mathrm{mg} / \mathrm{dl}$, and a spinal tap revealed that the cell count of cerebrospinal fluid (CSF) was 50/3 with 22\% neutrophils and $78 \%$ lymphocytes, glucose 74 $\mathrm{mg} / \mathrm{dl}$, and protein $38 \mathrm{mg} / \mathrm{dl}$ with negative microbiological study. Vasculitis was not demonstrated histopathologically in a specimen obtained from biceps muscle.

Stubborn headache, vestibuloauditory dysfunction, scleritis, aseptic meningitis, parotid swelling, facial nerve palsy and persistent positive inflam- 
matory indices were all compatible with Cogan's syndrome, and $60 \mathrm{mg} /$ day of prednisolone was started. As shown in Fig. 2, the headache, parotid swelling and scleritis disappeared within several days, and ESR, CRP and CSF findings also were normalized. CT scan and MRI obtained two wk after the initiation of prednisolone therapy demonstrated the resolution of pituitary swelling (Fig. 1B). The reassessment of pituitary function when the dose of prednisolone was tapered to $30 \mathrm{mg} /$ day revealed an increase in the basal level of TSH as well as a partial improvement of TSH response to TRH, and a normalization of basal prolactin (PRL) (Fig. 2 and Table 1). There were no remarkable changes in basal and stimulated levels of gonadotropins (Table 1), and a trial to withdraw DDAVP was not successful. Six months after the initiation of prednisolone she is well without any signs or symptoms of inflammation and is on $25 \mathrm{mg} /$ day of prednisolone.

\section{DISCUSSION}

The case presented here appears to be the first case of hypopituitarism associated with Cogan's syndrome. MRI clearly demonstrated a response of a presumed inflammatory pituitary lesion to highdose glucocorticoid.

Non-syphilitic interstitial keratitis with vestibuloauditory dysfunction was first described by Mogan and Baumgartner (4) in 1934, and was established as a clinical entity by Cogan (1) in 1945. Generally, Cogan's syndrome is diagnosed from variable ophthalmic lesions including the scleritis, auditory and vestibular symptoms and laboratory findings including mild to moderate leukocytosis, elevated ESR, positive CRP, normal complement levels and negative antinuclear antibody titers. Although the pathological basis of the syndrome is proposed to be systemic vasculitis resulting from allergic hypersensitivity or autoimmune mechanism, histopathological evidence has been demonstrated only in 12 cases among 119 cases reported. Of these cases with proven vasculitis, nine cases of periarteritis nodosa or necrotizing vasculitis (5-12), two cases of aortitis $(13,14)$ and a case with a lesion resembling Burger's disease (15) were reported.

At presentation, the present case had marked polydipsia and polyuria, directing our attention to the search for pituitary dysfunction. However, ophthalmic and vestibuloauditory lesions, slight fever along with leukocytosis, elevated ESR and positive CRP had indicated the presence of an inflammatory process consistent with Cogan's syndrome. Partial central diabetes insipidus was well controlled by nasal DDAVP administration, but secondary hypothyroidism developed concomitant with exacerbation of Cogan's syndrome, as indicated by the advent of left facial nerve palsy, parotitis, aseptic meningitis and further increment in CRP value. In accordance with the notion that Cogan's syndrome is a systemic disease arising from vasculitis, there are many reports of cases with additional clinical manifestations beyond the original description $(2,3)$. Although no case of Cogan's syndrome has been reported to accompany hypothalamic-pituitary lesion, the clinical features observed in this patient are best explained by the possibility of Cogan's syndrome causing the hypothalamic-pituitary dysfunction as an unusual associated clinical presentation. Central diabetes insipidus along with hyperprolactinemia suggested that the lesion extended from the pituitary stalk to the hypothalamus; the hypothyroidism with a lack of TSH response to TRH indicated damage to the pituitary itself.

Since no surgical procedure was performed, the pathological process leading to the pituitary dysfunction in the present patient could not be elucidated conclusively. Temporal arteritis which is a subtype of a vasculitis syndrome like Cogan's syndrome is included in the list of causes of hypopituitarism. The pathology of a pituitary lesion which was caused by temporal arteritis was reported to be ischemic necrosis (16), and the MRI appearance of our patient was not considered to be compatible with such an ischemic lesion.

The reversal of a diffuse swelling of the pituitary demonstrated by MRI after high-dose glucocorticoid therapy suggests the possible pituitary pathology of autoimmune-related lymphocytic or granulomatous giant cell hypophysitis, anecdotal lesions such as lymphoma, sarcoidosis, or eosinophilic granuloma. Lymphoma confined to hypophysis should be considered, but the absence of a mass effect to the surrounding structures along with benign CSF cytology renders the possibility of lymphoma to be low. The possibility of sarcoidosis is also low because 
of the absence of hilar lymphadenopathy, normal serum angiotensin converting enzyme activity and the positive tuberculin skin test. Although rare cases with diabetes insipidus and hypopituitarism whose parasellar masses were proved to be an eosinophilic granuloma have been described $(17,18)$, it usually presents as an infiltrative lesion. Lytic lesions of other bones characteristic to eosinophilic granuloma were not observed in our patient. Therefore eosinophilic granuloma is also unlikely.

Accordingly, although only through the exclusion of several pathological states above mentioned, we considered it most probable that the inflammatory process around the pituitary in the present patient occurred from a common pathological process to Cogan's syndrome, namely from an immunological process. Lymphocytic hypophysitis and giant cell granulomatous hypophysitis may be the representatives in this category. Although the lymphocytic hypophysitis has been often reported in young women in the peripartum period who developed hypopituitarism associated with a presumed pituitary tumor (19-23), giant cell granulomatous hypophysitis is seen primarily in middle aged or older women $(24,25)$. At present, the pathogenesis and interrelationship between these two entities are unknown, but an autoimmune inflammatory process is thought to be highly possible. Lymphocytic hypophysitis is often associated with other autoimmune phenomena (22), and the present patient had positive antithyroid antibodies and Cogan's syndrome which is presumed to be an autoimmune vasculitis.

Finally, the change in the serum TSH level after glucocorticoid therapy is noteworthy. The basal level of TSH, once undetectable, became detectable, and its response to TRH also recovered. Although the recovery of TSH was minimal, it appears to be meaningful especially because it was measured while the patient was taking a pharmacological dose of glucocorticoid, which is known to exhibit suppressive effects on basal and TRH-stimulated TSH (26). This, along with the MRI study, may indicate the possibility that the treatment with a high-dose glucocorticoid may reverse, at least partially, not only the anatomical but also the functional derangement of some pituitary lesions possibly associated with an autoimmune mechanism as assumed in this case.

\section{REFERENCES}

1) Cogan DG. Syndrome of nonsyphilitic interstitial keratitis and vestibuloauditory symptoms. Arch Ophthalmol 33: 144, 1945.

2) Cheson BD, Bluming AZ, Alroy J. Cogan's syndrome: A systemic vasculitis. Am J Med 60: 549, 1976.

3) Haynes BF, Kaiser-Kupfer MI, et al. Cogan syndrome: Studies in thirteen patients, long-term follow-up and a review of the literature. Medicine 59: 426, 1980.

4) Mogan RF, Baumgartner CJ. Menier's disease complicated by recurrent interstitial keratitis. Excellent result following cervical ganglionectomy. West J Surg 42: 628, 1934.

5) Oliner L, Taubenhaus M, Shapira TM, et al. Nonsyphilitic interstitial keratitis and bilateral deafness (Cogan's syndrome) associated with essential polyangitis (periarteritis nodosa). A review of the syndrome with consideration of a possible pathogenic mechanism. $\mathrm{N}$ Engl J Med 248: 1001, 1953.

6) Leff TL. Cogan's syndrome: Ocular pathology. NY State J Med 67: 2249, 1967.

7) Pinals RS. Cogan's syndrome with arthritis and aortic insufficiency. J Rheumatol 5: 3, 1978.

8) Crawford WJ. Cogan's syndrome associated with polyarteritis nodosa: A report of three cases. PA Med J 60: 835, 1957.

9) Del Carpia J, Espinoza LR, Osterland CK. Cogan's syndrome and HLA BW17. N Engl J Med 295: 1262, 1976.

10) Eisenstein B, Taubenhaus M. Nonsyphilitic interstitial keratitis and bilateral deafness (Cogan's syndrome) associated with cardiovascular disease. N Engl J Med 258: $1074,1958$.

11) Yamazaki M, Tanaka M, Miyatake T, et al. Cogan's syndrome with cerebral vascular disorder and histological findings of vasculitis. A case report. Shinkei Naika 22: 252, 1985 (in Japanese).

12) Kanehisa $Y$, Abe $K$, Takiyama $Y$, et al. A case of Cogan syndrome. Shinkei Naika 23: 591, 1985 (in Japanese).

13) Cogan DG, Dickersin GR. Nonsyphilitic interstitial keratitis with vestibuloauditory symptoms: A case with fatal aortitis. Arch Ophthalmol 71: 80, 1964.

14) Bernhardt D, Veltmann G, Huth RD. Cogan-Syndrome bei Angitis von Hirnnerven, Aortitis, Endokarditis und Glomerulonephritis. Dtsch Med Wochenschr 101: 373, 1976 (in German).

15) Fisher ER, Hellstrom HR. Cogan's syndrome and systemic vascular disease. Arch Pathol 72: 572, 1961.

16) Kovacs K. Necrosis of anterior pituitary in humans. Neuroendocrinology 4: 170, 1969.

17) Pressman BD, Waldron RL II, Wood EH, Histiocytosis$\mathrm{X}$ of the hypothalamus. Br J Radiol 48: 176, 1975.

18) Goodman RH, Post KD, Molitch ME, et al. Eosinophilic granuloma mimicking a pituitary tumor. Neurosurgery 5: 723, 1979.

19) Mayfield RK, Levine JH, Gordon L, et al. Lymphoid 
adenohypophysitis presenting as a pituitary tumor. Am J Med 69: 619, 1980.

20) Asa SL, Bilbao JM, Kovacs K, Josse RG, Kreines K. Lymphocytic hypophysitis of pregnancy resulting in hypopituitarism. Ann Intern Med 95: 166, 1981.

21) Baskin DS, Townsend JJ, Wilson CB. Lymphocytic adenohypophysitis of pregnancy simulating a pituitary adenoma: A distinct pathological entity. J Neurosurg 56: $148,1982$.

22) Mazzone T, Kelly W, Ensinck J. Lymphocytic hypophysitis: associated with antiparietal cell antibodies and vitamin $B_{12}$ deficiency. Arch Intern Med 143:
1794, 1983.

23) Jensen MD, Handwerger BS, Scheithauer BW, et al. Lymphocytic hypophysitis with isolated corticotropin deficiency. Ann Intern Med 105: 200, 1986.

24) Rickards AG, Harvey PW. "Giant cell granuloma" and other pituitary granulomata. Q J Med 23: 425, 1954.

25) del Pozo JM, Roda JE, Montoya JG, et al. Intrasellar granuloma: Case report. J Neurosurg 53: 717, 1980.

26) Sowers JR, Carlson HE, Brautbar N, Hershman JM. Effect of dexamethasone on prolactin and $\mathrm{TSH}$ responses to TRH and metoclopramide in man. J Clin Endocrinol Metab 44: 237, 1977. 